\title{
Per Ardua ad Astra (et Terram)
}

One swallow does not make a summer, but for people yearning to see the winter end, the sight of even a single swallow is bound to seem a cheerful omen. This is the spirit in which the managers of the United States National Aeronautics and Space Administration (NASA) will be glued to their television screens for the next few days, waiting to see whether the new reusable spacecraft, the shuttle, will succeed. With luck, the first version of the shuttle (called Columbia) will be launched on Friday this week, roughly two years later than first planned. Soon afterwards, it should be clear whether the spacecraft has found its way into an orbit about the Earth. Just over two days later, it may have found its way back again, to an airstrip in California. That is the plan. NASA officials will not be the only people biting their nails through this tense period. Several crucial scientific enterprises, the Large Space Telescope in particular, hang on the success of the shuttle. So do several important technical projects, the further development of the international telecommunications network for example. And while it is by no means clear what the Pentagon has in mind for this new means of putting things and people in orbit, the chances are that a success for Columbia this weekend will spark off a round of vigorous jockeying for priority in the launching timetable among the potential users. So much is easily predictable.

It is therefore churlish but also necessary, even at this late stage, to raise the question of what happens if Columbia fails. Ordinarily, if the shuttle were a more conventional spacecraft, the consequences of failure would be negligible. The managers at NASA would bite their lips, utter whatever stoical comments the circumstances of failure required - and set to on the readying of the next spacecraft from the production line. If Columbia fails, they will no doubt follow the same tack but with less conviction. With the budget for the next fiscal year still enmeshed in Congress, it is unlikely that they could escape the thorough investigation of the whole shuttle programme that they have managed to avoid in the past two years. And even if the first flight of Columbia is a success, it is now clear that the development of the shuttle has been too much of a scramble for comfort.

Of the problems that have beset (and delayed) development, the most serious is that concerned with the device for protecting the spacecraft from heat on reentry into the atmosphere. Recurring troubles with the ceramic tiles intended to accomplish this would have been comic if they were not also almost tragic. It has been forgotten that the tiles are a makeshift substitute for the wonder alloys foreseen when the shuttle was originally conceived of a decade ago, and which have not materialized. The other glaring deficiency in the development programme is the lack of flight experience. A single launching from the back of a Boeing 747 can hardly command confidence. By contrast, recurring problems with the rocket motors, which may nevertheless turn out to be disastrous, are largely a monument to the American passion for optimizing everything - never use a rocket motor off the shelf if there is a chance that a purpose-built motor might be slightly more efficient seems to be the motto. If Columbia fails this weekend, these questions are certain to be reopened.

Others than NASA officials should therefore keep their fingers crossed. The whole device may have been an imperfectly considered technological leap in the dark, but success promises a quantum jump in the utilization of orbits about the Earth. The planned reduction of cost (by roughly a factor of ten for unit mass placed in an orbit) is only a part of the promise. The possibility that the shuttle may be a means of maintaining and repairing satellites already in orbit is potentially more important. Whatever the outcome of this weekend's experiment, there is therefore the strongest possible case for NASA to spend a substantial part of its hard-won budget on a more satisfactory solution than the present of the heat-shielding problem. That cannot be a simple task. Heat-shields based on thermal insulators whose surfaces ablate at high temperatures, widely used to protect the warheads of longrange missiles, are plainly unsuitable for spacecraft intended to be used repeatedly. Solid insulators intended to get rid of heat by radiation are even more susceptible than others to destruction by thermal shock. But mechanical cooling systems based on circulating fluids are probably impractical - their mass would be too great. NASA has already let one contract, seeking an alternative solution. It should quickly cast its net wider. For the shuttle, for all its defects, it the best American spacecraft in sight.

\section{Who, not Congress, should police fraud?}

How often do scientists cheat? How seriously, in the process, is the scientific literature corrupted? And what, if anything, should be done to put a stop to the occasional transgressions that come to light? The United States Congress (see page 435) should not be surprised that it failed to answer these questions in its brief inquiry last week into a few of the cases of wrongdoing that have come to light in the past few months. On the other hand, there is no reason why the research establishment should resent the inquiry or even fear that the outcome will be a novel, intrusive and probably unworkable system of regulation imposed from Washington. There is no reason to suppose that Representative Albert Gore's subcommittee seeks to be a kind of arbiter of ethics in the research laboratory or that it plans to recommend some central system of regulation. The most sinister of the plausible motives for last week's inquiry is that the subcommittee, which plans next to take up more general (and important) issues such as the propriety of arrangements between academic scientists and commercial companies in the field of genetic engineering, the adequacy of agreed procedures for experiments with human subjects and the like, is seeking to demonstrate at the outset that not all scientists are, like Caesar's wife, above reproach.

The committee's inquiry would have been more productive if it had more clearly thought through the problem of malfeasance in research before dragging its impressive collection of witnesses to Washington last week. It should not have confined its inquiry to biomedical research, and it should have distinguished more clearly between the different kinds of misdemeanours that have from time to time become open scandals. The committee (and those who gave evidence last week) should also have had the wit to recognize that any formal central system for the prevention of misdemeanours is likely also further to inhibit freedom of access to the scientific literature. Journals and their referees are already sufficiently aware of the dangers of having wool pulled over their eyes. More restraint would diminish the chance that heterodox ideas would find their way into the light of day and further tip the scales against innovations.

Plagiarism, the most flagrant of misdemeanours, is paradoxically not as serious a cause for concern as some pretend. 